\title{
Proteção social: \\ trilhando considerações sobre o \\ sistema do vizinho Uruguai
}

\section{Social protection: along the paths of the system in neighbouring Uruguay}

\author{
Alan de Loiola Alves ${ }^{a}$ \\ (D) https://orcid.org/0000-0002-3089-7619 \\ Rosemeire dos Santos ${ }^{b}$ \\ (D) https://orcid.org/0000-0001-7172-4151
}

Resumo: 0 artigo propõe apresentar as direções do sistema de proteção social no Uruguai desde sua construção até a atualidade. Para isso foi realizado levantamento bibliográfico com caráter exploratório. Este estudo aponta que o sistema de proteção social uruguaio seguiu diferentes e, por vezes, múltiplas direções desde a lógica compensatória, solidária, universal, democrática, contributiva, de pleno emprego, regulada, repressora, até neoliberal.

Palavras-chave: Proteção social. Uruguai. Política social.

\begin{abstract}
The aim of this paper is to present the courses of action of the social protection system in Uruguay, since its inception until the present, for which bibliographical survey of exploratory nature was carried out. The results of the survey show that the Uruguayan protection system has followed diverse, sometimes multiple, directions, be them compensatory, solidaristic, universal, democratic, contributive, full-employment, regulatory, repressive, and even neoliberal.

Keywords: Social protection. Uruguay. Social policies.
\end{abstract}




\section{Introdução}

A conjuntura social contemporânea da América Latina é marcada por um conjunto de crises resultantes da crise flexível do capital, o que agrava as expressões da Questão Social e a refração dos direitos sociais. Pensando especificamente na realidade do Cone Sul, tal conjuntura provocou um enfraquecimento dos governos progressistas e de centro-esquerda que houve nos países da região nos últimos 20 anos, reorientando a lógica do capital com posições de extrema e/ou centro-direita e neoconservadoras, afetando diretamente o sistema de proteção social. Mas de que sistema de proteção social estamos falando?

Para tentar responder a essa indagação é que surgiu o interesse de conhecer o processo e as direções do sistema de proteção social uruguaio, pois este foi o último país da região a sofrer com o fechamento do ciclo de governos progressistas e um dos primeiros a implementar políticas sociais protecionistas dentro de suas contradições.

O Uruguai é um dos menores países da América do Sul, tanto em extensão como em quantidade populacional, mantendo nos últimos dez anos pouco mais de três milhões de habitantes. O censo de 2011 aponta que são 3.251.654, sendo 1.690.598 de mulheres e 1.561.056 de homens. Quanto à questão racial, a maioria da população é composta por pessoas brancas com ancestralidade espanhola e italiana, seguida por uma população negra, indígena e asiática, quase metade da qual habita na capital, Montevidéu. ${ }^{1}$

A expectativa de vida dos uruguaios é de 75.3 anos, possibilitando afirmar um alto índice de desenvolvimento humano. No entanto, o crescimento demográfico é negativo, uma vez que a taxa de natalidade é baixa, o envelhecimento é alto e ainda o país é marcado pela migração dos jovens para o exterior em busca de empregos, como destaca Castro (2017).

1 Dados consultados no site: http://www.ine.gub.uy/censos-2011. Acesso em: 24 maio 2019. 
Vale ressaltar que, atualmente, o salário mínino do Uruguai é de 16.300 mil pesos uruguaios, equivalendo a 2.119,42 reais, ${ }^{2}$ sendo o segundo maior salário mínimo da América Latina.

Para tanto, para conhecer as direções do sistema de proteção social do Uruguai, este ensaio está organizado em três momentos. O primeiro, uma breve contextualização teórica sobre proteção social. O segundo, a particularidade histórica do Uruguai, bem como da sua proteção social. E no terceiro momento, aborda-se o sistema de proteção social na contemporaneidade; isto é, a partir do final da ditadura militar em meados da década de 1980 até os governos progressistas do Partido Frente Ampla.

\section{Proteção social: tecendo considerações}

Discutir sobre proteção social é ter clareza de que não é uma discussão recente, todavia, primordial para a manutenção da vida e da sobrevivência dos seres humanos; corroborando a discussão de Di Giovanni (1998, p. 8), “[...] não existe sociedade humana que não tenha desenvolvido algum tipo de proteção social”. Na compreensão de que proteção social é um conjunto de providências objetivas e subjetivas para indivíduos e famílias frente às necessidades de vida e sobrevivência. Cabe ainda destacar que o provimento da proteção social se desenvolve tanto no âmbito privado, ou seja, lugar doméstico e/ou familiar, como no âmbito público, que resulta na externalização das condições e capacidades protetivas no círculo doméstico familiar.

Vale, ainda, dialogar que as primeiras manifestações de proteção social no âmbito público não são desenvolvidas e tampouco de responsabilidade do Estado, senão funções inicialmente de grupos de apoio, de solidariedade mútua e das instituições filantrópicas. Todavia, as ações passam a ser responsabilidade do Estado, principalmente no período

2 Conforme o câmbio do dia 24 de abril de 2020. 
pós-Segunda Guerra Mundial, cujos acordos internacionais se medeiam ao projeto desenvolvimentista de reorganização da ordem do capital mundial (Santos, 2017).

Isso, ao mesmo tempo, tem como proposta a manuteção da vida; nesse momento, o maior interesse é restabelecer a ordem capitalista da sociedade, por meio de benefícios e serviços disponibilizados à sociedade pelo Estado para estimular o consumo e as condições materiais de sobrevivência. Assim, os sistemas de proteção social originam-se a partir da emergência e das necessidades humanas, tanto de restabelecimento da ordem do capital como da necessidade de prevenção, redução e/ou diminuição de riscos a indivíduos ou grupos sociais.

Nessa perspectiva, é possível afirmar que as noções e os direcionamentos dos sistemas de proteção social público se demarcam, durante o século XIX, com a constatação de que a vulnerabilidade e a insegurança social se ampliavam à medida que se expandiam as relações de trabalho assalariado. Inseguranças causadas pelas relações da presença e da ausência do trabalho, como doenças, velhice, desemprego, morte, salários insuficientes para a manuntenção básica do trabalhador e seus familiares.

No processo de externalização e de responsabilidade estatal, a proteção social passa do nível da solidariedade entre classes para o nível de direitos sociais, uma vez que não institui apenas benefícios e serviços públicos, mas também os associa a um sistema de obrigações jurídicas e de cotizações obrigatórias, ao instituir a lógica do seguro social, que permitiu minimizar a situação de insegurança e vulnerabilidade da classe trabalhadora que permeava a situação do trabalhador assalariado. Foram essas as estratégias dos países capitalistas já que, por necessidade de proteção social para as condições de trabalho, empregadores e trabalhadores buscaram formas de proteção social sob a lógica do trabalho assalariado, resultando nas corporações de mutualidades e associações entre os trabalhadores e empregadores com regulação do Estado.

E em conjunturas políticas e econômicas de recessões, os Estados capitalistas apresentam como estratégia o exercício da proteção social a 
famílias e indivíduos, distinguindo-os entre "beneficiários e assistidos" (Sposati, 1988, p. 314), ou seja, indíviduos e famílias trabalhadoras possuem benefícios a partir da lógica contributiva, e indíviduos e famílias que não acessam o trabalho e dependem da política distributiva são "assistidas" e devem buscar sua autonomia e emancipação pela via do trabalho.

Na perspectiva do acesso ao "direito à proteção social" advinda do trabalho, constitui-se o que Santos (1979) conceitua de cidadania regulada, em que o Estado passa a reconhecer como cidadão de direitos protetivos somente indivíduos e famílias vinculados ao trabalho formalizado, ou seja, com os acessos aos seguros sociais disponíveis para a classe trabalhadora com o trabalho formal.

No ambiente de política pública, essas necessidades e fragilidades tramitam de situações individuais, pontuais para o campo de preservação e ampliação da vivência comum e coletiva, porque no momento em que as necessidades são reduzidas às individuais, tais só serão respondidas pela lógica de mercado.

Superando a lógica mercadológica instaurada nos sistemas de proteção social na sociedade capitalista, compreende-se que a proteção social, segundo Sposati (2008, p. 8), é “[...] investimento no futuro e na qualidade de vida pessoal e social, é um campo relacional e não meramente tutelar, mantenedor do status quo, o que significaria não ter ou, restringir à mesmice, o horizonte".

Além disso, compreender o sistema de proteção social é perpassar pela sua configuração como um complexo de legislação social, políticas públicas e sociais, questões econômicas, acesso real a serviços e investimentos públicos (erroneamente chamado de gastos públicos) que estão em torno de um denominador comum, ou seja, segurança e preservação (Sposati, 2008).

A referência de preservação aqui exposta não é a da preservação da precariedade ou da subalternidade entre classes sociais e sim de preservação da vida humana, com a direção social para o alcance dos princípios de equidade, liberdade, emancipação e cidadania. 
A partir disso, indaga-se: quais são as particularidades do sistema de produção e reprodução social do Uruguai e as direções do seu sistema de proteção social?

\section{Caminhos do sistema de proteção social no Uruguai}

A história do Uruguai é marcada pela colonização dos espanhóis, fazendo parte do Vice-Reino do Rio da Prata. Esse período colonial foi marcado por: pradaria, fronteira e porto. A criação do Estado Oriental do Uruguai se deu em 1828 com interferência do Reino Unido para minimizar os conflitos entre Brasil e Argentina, que buscavam controlar o Rio da Prata (Almeida, 2011).

Segundo Castellano (1996), o pós-colonialismo uruguaio tem uma característica marcada por uma relativa estabilidade e prosperidade pecuária depois do fim da guerra civil em 1851, e com a consolidação dos direitos políticos e dos direitos sociais, pois em 1870 já havia duas tendências políticas: Partidos Blanco e Colorado.

O Partido Colorado detém o poder político no Uruguai com o período chamado de reformismo Batllismo que, marcado pelas ideias reformistas de José Batlle y Ordóñez (presidente entre 1903-1907 e 1911-1915), tratava de uma estratégia de estatização, de nacionalização, de protecionismo industrial e pretendia mexer com a estrutura da propriedade da terra, o que gerava opositores.

O período inicial de proteção social no Uruguai se deu no final do século XIX e se expandiu nas três primeiras décadas do século XX através da articulação do modelo de desenvolvimento e bem-estar do governo Batllista, ocorrendo a consolidação dos direitos políticos e a consagração dos direitos sociais simultaneamente; de caráter progressista e universal, com extensa participação política de importantes segmentos da população e com a implementação das políticas sociais.

Em 1877 é instituída a Lei da Educação, sendo definida como laica, gratuita e obrigatória, apresentando em 1900 uma taxa de alfabetização 
de 54\% da população. A partir de 1912 se experimentou um desenvolvimento do ensino médio no interior e para as mulheres, assim como a fundação de novas universidades e ingresso das mulheres (Almeida, 2011).

A política de assistência social foi decretada no Uruguai em 1910, sendo ressaltado nesta lei que o "[...] direito à assistência é uma compensação das injustiças sociais e uma consequência da solidariedade” (tradução nossa), ${ }^{3}$ (Di Carlo, 1966, p. 14 apud Acosta, 2014, p. 188). Com base em Di Carlo (1966, p. 14 apud Acosta 2014, p. 187-188), pode-se destacar que a assistência social nesse país foi regulamentada através do princípio da universalidade e de reparação parcial para os seres humanos quem sofrem "as consequências negativas que advêm dos riscos da vida individual, familiar e coletiva”.

A proteção social uruguaia foi impulsionada pelo Movimento $\mathrm{Mu}$ tualista, que consistia na assistência médica por meio das sociedades de socorros mútuos, que se iniciou em meados do século XIX, favorecendo inicialmente o proletariado de origem europeia, os pequenos comerciantes e os trabalhadores informais (autônomos). E, já nas primeiras décadas do século XX, a classe média começou a vislumbrar as vantagens desse movimento, assim como serviu para o "Proselitismo confessional (Hospital Evangélico e Círculo Católico de Obreros)" e para o "Campo político-ideológico (Partido Nacional e Partido Colorado)", como destaca Mardones (2007, p. 30, grifos do nossos).

Todavia, a expansão da proteção social no Uruguai se deu na lógica do trabalho, na qual foram criadas leis e políticas para os trabalhadores, tais como Caja de Jubilaciones Civiles (1904), Oficina Nacional del Trabajo (1907), lei de acidentes de trabalho e indenização por demissão (1914), jornada de trabalho de oito horas para os trabalhadores da indústria (1915), Lei de Proteção ao Trabalho Feminino (1918) e Lei de Descanso Semanal (1920). Ainda, foi estabelecido, em 1919, o sistema de previdência social, de alcance relativamente universal.

3 Texto original: "[...] derecho a la asistencia es una compensación de las injusticias sociales, y es una consecuencia de la solidaridad" (Di Carlo, 1966, p. 14 apud Acosta, 2014, p. 188). 
Cabe ressaltar que os direitos políticos no Uruguai são datados a partir de 1917 com a Reforma Constitucional, instituindo o Sufrágio Universal, que entra em vigência em 1919, e o voto feminino, que foi legitimado em 1927, sendo assim o país pioneiro na América Latina.

A política de assistência social foi instituída pela criação da Asignación Familiar (AF) em 1943 para apoiar os trabalhadores do comércio, da indústria e dos escritórios das instituições privadas, chefes de família, pela qual eram concedidos benefícios para os filhos (até 14 anos, ou 16 anos, caso o filho ainda estivesse estudando), sendo excluídos dos benefícios os filhos dos trabalhadores rurais e dos serviços domésticos. De acordo com Casaña (2018), a AF visava neutralizar as potencialidades revolucionárias da classe trabalhadora.

Entre 1954 e 1958, ocorreram ampliações significativas nas Asignaciones Familares com a inclusão para acesso aos benefícios de famílias de trabalhadores rurais e com a criação de novos benefícios, tais como: salário-maternidade, serviço materno-infantil (pré-natal, parto e pós-parto), lar constituído, bônus por matrimônio, bônus por nascimento de cada filho, colônia infantil de férias, bolsas de estudo e salário-família (Casaña, 2018).

Outra medida de proteção social para os trabalhadores foi a criação do Banco de Previsión Social (BPS) em 1967, que regia o sistema previdenciário, arrecadando e controlando os fundos que eram destinados às Asignaciones Familares. Além disso, o BPS fomentou a criação do Ministerio de Trabajo y Seguridad Social nesse mesmo ano (Caristo, 2005). E Acosta (2014) acrescenta que foi promulgada a Lei de Moradia em 1968, reconhecendo a moradia como um direito social.

Vale salientar que, até o início da década de 1970, o Uruguai tinha taxas elevadas de formalização do emprego, garantindo assim uma cobertura social de $95 \%$ da população economicamente ativa, possibilitando a universalização da proteção pelo trabalho, e as “[...] ações conhecidas como de assistência eram concebidas como complementares (e necessariamente articuladas) com as diferentes políticas sociais permanentes de corte mais universalista", como destacam Pastorini e Martínez (2014, p. 64). 
Diante disso, percebe-se que o Uruguai chegou a vivenciar um regime social-democrático, pautado na tentativa de um regime de bem-estar capitalista voltado para o mundo do trabalho.

A ditadura militar (1973-1984) foi marcada pela suspensão da cidadania política, pela ordem reacionária e conservadora, porém sendo realizada abertura econômica; e inicia-se um processo de desregulamentação da proteção social instituída até o momento (Soto, Lima e Tripiana, 2018). Nesse período, foram utilizados instrumentos de repressão da seguridade social por meio de realocações da despesa pública, como a extinção dos Consejos de Salarios e alterações nas Asignaciones Familiares (Decreto Lei n. 15.084, de 1980), que deixavam de ser subsidiadas pelos empregadores para ser financiadas pelo Estado, como também foi estendida a cobertura para todos os trabalhadores do setor privado, cujo objetivo era o de reduzir os custos de mão de obra (Almeida, 2011).

\section{A proteção social no Uruguai na contemporaneidade}

A primeira metade da decáda de 1980 no Uruguai foi marcada pelo processo de redemocratização do país com o fim da ditudura militar, mas o período autoritário e repressivo deixou marcas profundas na economia; isto é, endividamento externo e interno, altas taxas de inflação e aumento do desemprego. Concomitantemente, a conjuntura mundial foi marcada pela crise mundial do capital, pela globalização financeira, pela "queda do mundo socialista" e pela reestruturação produtiva, reconfigurando os Estados-nações. Esse cenário impulsionou as reformas com tendências neoliberais no âmbito econômico nesse país, uma vez que o Consenso de Washington influenciou e direcionou para a realização do "pacote de ajuste estrutural", provocando alterações no sistema de proteção social.

Cabe destacar que foi nesse período que o ideário do neoliberalismo insere o capitalismo avançado não só no Uruguai, mas também consistindo em uma tendência na América Latina, fazendo com que o Estado aplique uma disciplina orçamentária com contenção de gastos na esfera 
social, priorizando a privatização, com cortes aos gastos sociais, não assumindo uma posição intervencionista nas expressões da questão social.

No governo de Luis Alberto Lacalle (Partido Nacional), no início dos anos 1990, o país abriu sua economia através do processo de privatização das estatais e implementação de reformas sociais, tais como: suspensão dos mecanismos de negociação salarial entre trabalhadores, empregadores e o Estado, aposentadoria baseada no regime de capitalização individual e administrada pelo setor privado, e reformulação ou criação de programas e projetos focalizados em crianças, adolescentes e idosos, como apontam Pastorini e Martínez (2014). E Abbate (2018) acrescenta que as políticas trabalhistas foram na verdade para flexibilizar e desregulamentar os direitos do trabalhador.

Entretanto, cabe destacar que “[...] o Estado não conseguiu privatizar as empresas públicas por causa do plebiscito de 1992, contra a chamada Ley de Empresas Públicas, que buscava impor o processo de privatização" (Pastorini e Martínez, 2014, p. 61). Castro (2017, 22) aponta que “[...] 72\% dos uruguaios decidiram que os serviços essenciais continuariam sendo públicos".

Contudo, a reforma da previdência foi aprovada em 1995, sendo caracterizada por um sistema misto de semiprivatização da seguridade social com organização de repartição complementar. O regime de repartição é responsável por um benefício universal; porém, este garante aposentadorias mais baixas e o regime complementar é direcionado para as pessoas com renda mais elevada, que contribuem compulsoriamente para o regime de capitalização individual, financiando aposentadorias mais elevadas (Amaro, 2000).

Além da reforma da previdência, foi feita uma reforma fiscal (1995), sendo retirada a prestação dos trabalhadores que recebiam rendas maiores que dez salários mínimos; assim, como apontam Soto, Lima e Tripiana (2018), esta estabeleceu a perda do caráter universal da assistência social entre os trabalhadores formais, sendo incrementado o montante para os lares de crianças e adolescentes (18 anos incompletos), rendas 
através da Lei n. 17.139, de julho de 1999, criando um regime assistencial paralelo dirigido aos titulares do benefício que tivessem esgotado sua cobertura de seguros de desemprego e às mulheres que fossem o único sustento do lar.

Todavia, o final da década de 1990 e o início dos anos 2000 no Uruguai foram marcados por uma forte crise econômica e social, acontecendo redução do PIB, aumento da inflação e do desemprego, e aumento dos índices de pobreza absoluta. A motivação para o agravamento dessa crise se dá em função da desvalorização do real brasileiro em 1999 e da crise econômica na Argentina em 2001 (Almeida, 2011).

No processo de reativação econômica pós-crise, se dá o processo de eleição de Tabaré Vázquez (2005-2010) do partido progressista Frente Ampla. ${ }^{4}$ Assim que esse governo assume o poder é criado o "Ministerio de Desarrollo Social - MIDES”, como uma previsão de retomada de um Estado interventor. O MIDES tem como finalidade integrar, coordenar e avaliar as políticas sociais intersetoriais destinadas a pessoas ou famílias em situação de vulnerabilidade social, como destacam Sátyro et al. (2019). Ainda, como acrescenta Abbate (2018), as áreas prioritárias de intervenção foram: infância, juventude, mulher, famílias empobrecidas, idosos e deficientes. ${ }^{5}$

Segundo Vecinday (2017, p. 207, tradução nossa), "os programas sociais realizados pelo MIDES são implementados mediante contratos com organizações da sociedade civil, que não param de se multiplicar [...]".

Já no primeiro ano de existência, o MIDES desenvolve o "Programa de Atención Nacional para la Emergencia Social — PANES”, um programa

4 "A Frente Ampla (FA) foi fundada em 5 de fevereiro de 1971 por uma coalizão de vários partidos políticos de orientação democrática, socialista e comunista (não ganhou as eleições neste ano)" (Castro, 2017, p. 22).

5 O MIDES incorporou e reconfigurou entidades e programas sociais, tais como: "Instituto del Niño y el Adolescente del Uruguay — INAU”; "Instituto Nacional de la Juventud — INJU”; "Instituto de la Mujer - Inmujeres"; e "Programa especial de família - Infamilia" (Abbate, 2018).

6 Texto original: "Los programas del MIDES son implementados mediante contratos con organizaciones de la sociedad civil que no han dejado de multiplicarse [...]". 
guarda-chuva, como base inicial da intervenção pública transitória, ou seja, para funcionar de 2005 a 2007, tendo como foco uma estratégia de emergência social (nutricional e sanitária) e apoio alimentar, e no alojamento de pessoas em situação de rua (consideradas indigentes) (Pastorini e Martínez, 2014). Esse programa tinha como finalidade "promover a integração social dessa parcela da população no sistema de proteção social nacional”, conforme apontam Sátyro et al. (2019, p. 139). As principais ações do PANES foram o "Ingreso Ciudadano - IC" e a Tarjeta Alimentaria.

O "IC" tinha três frentes de ação: 1 - A transferência de renda em que cada lar participante recebia mensalmente 1.360 pesos uruguaios e tinha como condicionalidades que os/as provedores/as de família se responsabilizassem pelo controle médico e pela permanência das crianças no sistema educacional; 2 - A experiência do primeiro emprego/ trabalho a jovens (18-29 anos) que se encontrassem em situação de risco social, vulnerabilidade e/ou pobreza; 3 - A criação de refúgios noturnos, diurnos e equipe móvel para atendimento à população em situação de rua (Almeida, 2011).

A Tarjeta Alimentar foi um Plano Alimentar implantado em 2006 com o intuito de incrementar a garantia de compra do Uruguai, organizado pelo sistema de distribuição de um cartão para compra - sobre o Programa ver o site do MIDES - , podendo ser considerado uma complementação do programa Ingreso Ciudadano (Almeida, 2011).

Em 2007, o PANES foi substituído pelo Plano de Equidade, que foi criado como um mecanismo estratégico permanente para reorganizar a proteção social, promovendo um conjunto de transformações na previdência social e nas ações assistenciais, assim como visando estabelecer uma proteção integrada através de reformas tributárias, saúde, emprego, habitação e educação (Pastorini e Martínez, 2014).

Na área da assistência social, o Plan de Equidad deu continuidade ao Plano Alimentar iniciado no PANES e desenvolveu um novo modelo de "Asignaciones Familiares", isto é, o “Asignaciones Familiares y Pensiones a 
la Vejez" (AFAM-PE), cujo objetivo era de atingir todos os domicílios com crianças e adolescentes que se encontrassem em situação de pobreza. Para acessar ao benefício, foi reformulado o Índice de Carências Críticas (ICC), consistindo num algoritmo que determina um limiar de vulnerabilidade, combinando diversas dimensões, tais como educação, renda e condições de moradia (Casaña, 2018).

A AFAM-PE estabeleceu como condicionalidades a comprovação de que o beneficiário recebe assistência e controles médicos regulares, a tramitação da carteira de identidade após os 45 dias do nascimento, a frequência à educação primária a partir dos quatro anos e até os 14 anos, e à educação média até os 18 anos. Ainda, determinou a necessidade de os beneficiários participarem de programas de promoção social. Além disso, a AFAM-PE estabeleceu o aumento dos controles das condicionalidades, isto é, criou um sistema único de registro integrado de informação do Estado (SIIAS), consistindo na informatização dos dados dos usuários para o Banco de Previsão Social, a fim de controlar que os beneficiários cumpram com as condicionalidades estabelecidas (Casaña, 2018).

A AFAM-PE continuou a fortalecer o ideário neoliberal, com uma força das ações do Estado mínimo, responsabilizando o indivíduo pelas manifestações da Questão Social, transformando ou reafirmando que os membros infantis ou adolescentes das famílias são encarregados também pelo sustento dos familiares. Além disso, esse programa estabelece formas de controle aos beneficiários.

Na educação se deu uma reforma através da Lei de Educação e do "Plan Ceibal" (2008), que pretendia desenhar um Sistema Nacional de Educação, gerando inovações em vários âmbitos por meio de uma complexa estrutura institucional que incluía a administração do ensino, a coordenação de suas instâncias, a descentralização, a participação de diversos atores sociais e a avaliação do sistema. O "Plan Ceibal" tratava-se de uma proposta de inovação educativa através da informática básica para a aprendizagem on-line, a qual consistia na entrega de um computador portátil a cada aluno do ensino público. Todavia, isso aconteceu em 
função de um acordo entre o órgão encarregado da Educação Primária (ANEP) com a empresa estatal de telecomunicações (ANTEL), como aborda Almeida (2011). Além desse Plano, foram incluídos nos currículos a história recente, o debate de educação sexual e dos direitos humanos (Abbate, 2018).

Outra reforma realizada nesse período foi a reforma na área da saúde, que se deu através da criação do SNIS (Sistema Nacional Integrado de Saúde) de 2007 e iniciado em 2008, que reúne os diversos prestadores de saúde do país, tanto públicos como privados, estabelecendo um novo modelo, podendo-se optar entre o chamado "Sistema Mutual Privado" ou o "Sistema de Salud Pública”. Nesse Sistema foi criado o Fondo Nacional de Salud (FONASA), que estabeleceu as contribuições obrigatórias feitas pelos trabalhadores de acordo com sua renda, capacidade de pagamento e estrutura familiar, e também descentralizou o serviço de administração de saúde do Estado, o Administración de Servicios de Salud del Estado - ASSE (Almeida, 2011).

Conforme aponta Abbate (2018), essa reforma na saúde promoveu um novo lugar do Ministerio de Salud Pública, mantendo o setor público como prestador de serviços através do ASSE, que concentra as bases do Sistema Nacional Integrado de Salud (SNIS) e do Seguro Nacional de Salud (SNS) com a perspectiva universal. Todavia, Vecinday (2017) ressalta que o ASSE acabou ficando para a população mais empobrecida, já que não consegue custear o sistema privado.

Na área do trabalho, foi implementado o Programa "Uruguay Trabaja”, que funcionou de 2008 a 2010, prevendo a ocupação protegida por um período de nove meses para pessoas que estavam desempregadas há pelo menos dois anos. As pessoas recebiam obrigatoriamente uma capacitação para duas finalidades, isto é, para reformar edifícios públicos com um salário de 3.844 pesos uruguaios e outra para trabalhar em empresas subsidiadas pelo Estado (Almeida, 2011).

Nesse período, foram promulgadas algumas leis trabalhistas, protegendo a organização e algumas categorias laborais, por exemplo, a lei de 
liberdade sindical, regulamentação do trabalho doméstico e da jornada de trabalho de oito horas para o trabalhador rural, com também foram estabalecidas normatizações legais para regulamentação da terceirização e de subcontratação, oficializando a precarização do trabalho. Ainda, Castro (2017) aponta para a retomada dos Conselhos de Salários, que era um espaço de negociação coletiva, recuperando a importância no debate do movimento sindical e do Ministério do Trabalho.

Na área da habitação, o processo de reforma teve duas grandes ações: a criação da "Agencia Nacional de Vivienda (ANV)" (2007) e o Programa "Atención a los Sin Techo" (2009). A Agencia foi criada como forma de descentralizar a ação do Estado nesse setor, tendo como finalidade "facilitar" o acesso ao crédito, seguindo três direções: 1) moradia social: o Ministerio de Vivienda, Ordenamiento Territorial y Medio Ambiente (MVOTMA) subsidia parcial ou totalmente residências para as famílias empobrecidas cadastradas; 2) moradia de interesse social: gerada através de uma rede formada por financiadores, fornecedores, Estado e "clientes", porém existe autonomia dos financiamentos por parte setor privado e um controle mínimo do Estado no que refere as normas; 3) mercado imobiliário, destinado para pessoas que possuem acesso à moradia através da renda (Abbate, 2018).

Agora, o Programa "Atención a los Sin Techo", cujo objetivo era a reinserção sociocultural e econômico-laboral de pessoas em situação de rua, buscando aliviar as condições em que vivem e também construir uma rota de saída efetiva e sustentável, no entanto, não garantiu direito à moradia para a população em situação de rua, consistindo-se em emergencial e imediatista (Almeida, 2011).

O segundo mandato da Frente Ampla se dá com a eleição de Mujica (2010-2015), que deu sequência às reformas no sistema de proteção social, continuando com as medidas do Plan de Equidad; porém, concentrando maior atenção à população em situação de extrema pobreza, expandindo a cobertura dos programas de transferência aos grupos marginalizados (Sátyro et al., 2019). Nesse aspecto, foi implantada a “Tarjeta Uruguai 
Social Trans" - TUS (2012), vinculada ao MIDES, uma política de ação afirmativa para a população transexual, criada em função das lutas dos movimentos sociais da população transexual (Gainza, 2014).

Esse governo assumiu um compromisso com a defesa de liberdades e direitos humanos com a aprovação da Lei do Aborto (2012), do Matrimônio Igualitário (2013), da Legalização da Maconha (2014), como destaca Castro (2017). Abbate (2018) salienta que nesse momento foram realizadas inovações no âmbito da gestão de recursos humanos, nas políticas de saúde sexual e reprodutiva, e saúde mental e drogas.

Além disso, nesse governo foram realizados investimentos para a democratização do sistema público de educação, aumentando a remuneração dos funcionários da educação e instituindo um conselho e um sistema de avalição, sendo eles: "Consejo de Formación en Educación - CFE" e "Instituto Nacional de la Evaluación Educativa”. Ainda, foram sancionadas a regulamentação do trabalho juvenil e a do trabalho noturno (Abbate, 2018).

De acordo com Pastorini e Martínez (2014, p. 64) com base em Morás (2010), a partir de 2010, percebe-se “[...] uma mudança no desenho das políticas de seguridade, que indicaria o abandono do horizonte da emergência social colocando no seu lugar a emergência carcerária”.

O terceiro e último momento (até então) do governo progressista comandado pela Frente Ampla se deu com a volta ao poder de Vázquez (2015-2020). Esse período foi marcado por uma desaceleração do crescimento econômico, em função da situação dos países "parceiros" comerciais, em especial China, Brasil e outros países da América Latina, contrariando os rumos dos dois governos anteriores, que vivenciaram expansão das exportações dos produtos agropecuários e com os investimentos estrangeiros diretos.

A respeito do sistema de proteção social, esse governo assumiu tendo como prioridade a "questão educacional"; porém, em função das pressões dos sindicatos da educação, não realizou nenhuma mudança, como aponta Vecinday (2017). Além disso, como ressalta Casaña (2018), 
no final de 2015 o MIDES se pronunciou contrário à rigidez do controle e dos recortes massivos na AFAM-PE; entretanto, nenhuma alteração foi realizada, dando assim continuidade às reformas sociais aplicadas nos governos anteriores da Frente Ampla.

\section{Considerações finais}

A intenção nem de longe pretendeu esgotar a discussão sobre o sistema de proteção social no Uruguai, mesmo porque tal pretensão é a-histórica e tão pouco dialética; todavia, o trabalho em suas reflexões evidencia que a proteção social no Uruguai, com seu pioneirismo nas pautas das políticas sociais no cone sul da América, experimentou diversas direções ao longo da história.

A direção social desenvolvida no sistema de proteção social iniciado nas três primeiras décadas do século XX se dava através da lógica compensatória e de solidariedade. Quando na perspectiva de universalização e de democratização dos direitos sociais e políticos, centrava-se no Estado a provisão dos bens sociais e da regulação social, em que ocorre uma proteção social direcionada ao trabalho formalizado, já que o intuito era de atender aos problemas do mundo do trabalho e de integração social via trabalho, reafirmando a lógica da cidadania regulada com base no trabalho urbano; e, na segunda metade do século XX, estendendo aos trabalhadores rurais, porém sem igualar as condições de trabalho entre trabalhadores urbanos e rurais, chegando próximo do modelo de pleno emprego.

No período ditatorial, o país passou a vivenciar as reduções das ações estatais de proteção social, utilizando-se do binômio "repressão e assistência”, em que para o acesso a serviços e benefícios a população devia obediência ao Estado. Além disso, foi um período marcado pelo endividamento externo e interno, altas taxas de inflação e aumento do desemprego.

A direção da proteção social no processo inicial de redemocratização do país foi impulsionada pelas reformas neoliberais, que promoveram 
uma diminuição do Estado através da privatização; dos cortes de gastos sociais; e da implantação das reformas sociais de caráter mínimo, focalista e controlador.

A ascensão do Partido Frente Ampla apresentou contradições no que tange ao avanço e à implementação das políticas de proteção social, pois, embora tenha tido um amplo investimeno do Estado, seguiu com ações neoliberais de caráter mínimo, focalista, controlador, principalmente no que concerne aos benefícios de transferência de renda, que impõe à população condicionalidades e responsabilidades a indivíduos e famílias. Além disso, instaurou sistemas de reformas na área da previdência, da saúde e da assistência social, acarretando a privatização e o aumento de taxas e tributos para a classe trabalhadora.

Nesse sentido, identifica-se que o sistema de proteção social do Uruguai convive com as perspectivas protecionista, produtivista, familista e controladora, via condicionalidades de acesso a serviços e benefícios, como também o acompanhamento exigido dos executores da proteção social.

Contudo, faz-se necessário aprofundar os estudos sobre a participação e o controle social por parte de indivíduos e famílias uruguaias no sistema de proteção social, bem como as políticas sociais que compõem, observando e estudando temáticas que são fundantes e necessárias no desenvolvimento e no planejamento da proteção social, tais como desenvolvimentos geracionais, gênero, raça/etnia, formação sócio-histórica, assim como aprofundar os estudos sobre os movimentos sociais na luta pelas políticas de proteção social e as demandas da população uruguaia em tempos de novas crises, de pandemia e outras formas de governabilidade.

Ao findar este trabalho, suscintou-se uma nova indagação: quais serão as direções do sistema de proteção social com este novo governo de direita que assumiu o poder em 2020? Neste momento não há como termos respostas; porém, a reflexão que se possibilita é de que a classe trabalhadora será mais uma vez desafiada a resistir e lutar para a construção de um sistema protetivo na perspectiva universal. 


\section{Referências}

ABBATE, A. S. C. Los trabajadores sociales en el Uruguay de la última década: sus espacios ocupacionales y condiciones de trabajo. 2018. Tese (Doutorado em Ciências Sociais com especialização em Trabalho Social) - Universidad de la República del Uruguay, Montevideo, Uruguay, 2018.

ACOSTA, L. O processo de renovação do Serviço Social no Uruguai. Em Pauta, v. 12, p. 181-203, 2014.

ALMEIDA, L. H. S. S. M. O papel do Estado no Uruguai contemporâneo: políticas públicas e bem-estar social (2005-2009). 2011. Dissertação (Mestrado em Estudos Comparados sobre as Américas) — Universidade de Brasília, Brasília, 2011.

AMARO, M. N. Previdência social na América do Sul. Consultoria Legislativa, 12 set. 2000. Disponível em: https://www2.senado.leg.br/bdsf/bitstream/handle/id/146/51. pdf?sequence=4. Acesso em: 24 maio 2019.

CARISTO, A. Asignaciones familiares en el Uruguay. Comentarios de Seguridad Social, n. 8, jul./ago./set. 2005. Disponível em: https:/www.bps.gub.uy/bps/file/1781/1/asignacionesfamiliares-en-el-uruguay.-a.-caristo.pdf. Acesso em: 25 maio 2019.

CASAÑA, M. S. C. Programa de Asignación Familiar del Plan de Equidad: uma avaliação política da política. 2018. Dissertação (Mestrado) — Universidade Federal do Maranhão, São Luís, 2018.

CASTELLANO CHRISTY, E. Uruguay: un caso de bienester de partidos. Revista Uruguaya de Ciencia Política, v. 9, p. 107-126, 1996.

CASTRO, M. S. P. de. Uruguai. São Paulo: Editora Fundação Perseu Abramo, 2017. (Coleção Nossa América Nuestra).

DI GIOVANNI, G. Sistemas de proteção social: uma introdução conceitual. In: OLIVEIRA, M. A. (org.). Reforma do Estado \& políticas de emprego no Brasil. Campinas: Instituto de Economia, Unicamp, 1998.

GAINZA, P. P. Acciones afirmativas: una herramienta de implementación de los derechos humanos. El caso de la Tarjeta Uruguay Social para población trans. ARACÊ: direitos humanos em revista, Montevideo, ano 1, n. 1, 2014.

MARDONES, C. G. Sistemas previdenciários sul-americanos: Brasil, Uruguai e Chile. Piracicaba: Universidade Metodista de Piracicaba, 2007.

MORÁS, L. E. Los dilemas y desafios de las politicas progresistas de la seguridade. Revista Encuentros Uruguayos. Montevideo, n.3 p. 6-21, set/2010.

PASTORINI, A.; MARTÍNEZ, I. Tendências das mudanças da proteção social no Brasil e no Uruguai: a centralidade das redes mínimas na América Latina. Katálysis, Florianópolis, v. 17, n. 1, p. 59-67, jan./jun. 2014. 
SANTOS, R.; DAL BELLO, M. G. (org.). Família que vive do trabalho e proteção social. Rio de Janeiro: Autografia, 2017.

SANTOS, W. G. dos. Cidadania e justiça: a política social na ordem brasileira. Rio de Janeiro: Campus, 1979.

SÁTYRO, N. et al. Comparando políticas sociais em governos de esquerda. Caderno CRH: revista do Centro de Estudos e Pesquisas em Humanidades, Salvador: UFBA, v. 32, 2019.

SOTO, S. F.; LIMA, V. F. S. A.; TRIPIANA, J. D. Transformações do sistema de proteção social no contexto latino-americano e antecedentes políticos e institucionais dos Programas de Transferência de Renda Condicionada (PTRC). In: SILVA, M. O. S. e (coord.). O mito e a realidade no enfrentamento à pobreza na América Latina: estudo comparado de programas de transferência de renda no Brasil, Argentina e Uruguai. São Paulo: Cortez, 2016.

SPOSATI, A. Vida urbana e gestão da pobreza. São Paulo: Cortez, 1988.

SPOSATI, A. Proteção social na América Latina em contexto da globalização. In: PRÉCONFERENCIA BRASILEIRA, 9 a 11 abr. 2008, Rio de Janeiro. Anais [...]. Rio de Janeiro: CBCISS - Centro Brasileiro de Cooperação e Intercâmbio de Serviços Sociais; Faculdade de Serviço Social da UFRJ, 9 a 11 abr. 2008.

VECINDAY, L. La reingeniería de la política asistencial en el Uruguay "progresista” y sus repercusiones para el trabajo social. In: SILVIA, Cecilia (coord.). TRANSFORMACIONES SOCIALES, PROTECCIÓN SOCIALI Y TRABAJO SOCIAL; CONGRESO NACIONAL DE TRABAJO SOCIAL, 12., 2017, Montevideo. Anais [...]. Montevideo: Udelar, 2017.

\section{Sobre os autores}

Alan de Loiola Alves - Doutorando em Serviço Social.

E-mail: alanloiola@yahoo.com.br

Rosemeire dos Santos - Doutora em Serviço Social. Professora adjunta da Pós-Graduação e da Graduação do curso de Serviço Social.

E-mail: rosemeiresantossp@gmail.com 